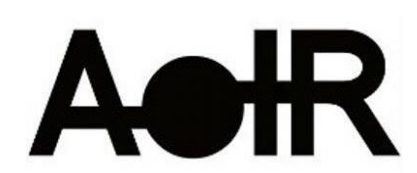

Selected Papers of \#AoIR2020:

The 22nd Annual Conference of the

Association of Internet Researchers

Philadelphia, PA, USA / 13-16 Oct 2021

\title{
GUY NEXT DOOR AND IMPLAUSIBLY ATTRACTIVE YOUNG WOMEN: THE VISUAL FRAMES OF SOCIAL MEDIA PROPAGANDA
}

\author{
Marco Bastos \\ University College Dublin, Ireland \\ Dan Mercea \\ City, University of London, United Kingdom \\ Fabio Goveia \\ Federal University of Espírito Santo, Brazil
}

\section{Extended abstract}

The research question driving this study is that tropes of heroic resistance or military endurance, typical of canonical state propaganda, track poorly in a context of information but not attrition warfare. We probe this question by taking stock of studies in visual propaganda research and testing whether social media propaganda seeks to embody the vox populi by employing relatable, familiar, or alternatively attractive faces of ordinary people-the archetypal "man on the street" (MOTS). We refer to such familiar or attractive faces as 'the guy next door' and the 'implausibly attractive young woman.' The former is embodied by an unassuming yet average male lacking overt tropes of hegemonic masculinity like strength and dominance commonly embraced by Russian propaganda (Romanets, 2017), while the latter is characterized by tangible exploitation of the female body for maximum erotic impact and objectification (Davis, 2018).

To this end, we analyzed the visual frames in profile images released by Twitter's Elections Integrity, which identified and removed the universe of false accounts operated by the Internet Research Agency (Elections Integrity, 2018). We sampled the data across five groups: Muscovites, BlackLivesMatter activists, Conservatives, Trump supporters, and Christians. We identified Russian accounts by querying the database for users that self-reported "Москва" as their location $(n=206)$. Next, we identified

Bastos, M.; Mercea, D.; Gouveia, F. (2021, October). Guy Next Door and Implausibly Attractive Young Women: The Visual Frames of Social Media Propaganda. Paper presented at AolR 2021: The 22nd Annual Conference of the Association of Internet Researchers. Philadelphia, PA, USA: AoIR. Retrieved from http://spir.aoir.org. 
Conservatives, Trump, Christian, and BlackLivesMatter supporters by sampling profiles with the keyword "Conservative" in the profile description $(n=121)$ and repeated the process (without replacement) for the keywords "Trump" ( $n=134)$, "God," "Christ," or "Jesus" ( $n=154)$, and finally "Black" or "BLM" $(n=79)$. After removing false positives and disambiguating profiles with multiple matches, the sampled data returned 75 BlackLivesMatter activists, 61 Christians, 104 Conservatives, 201 Muscovites, and 57 Trump supporter profiles. Figure 1 provides an overview of the profiled groups.
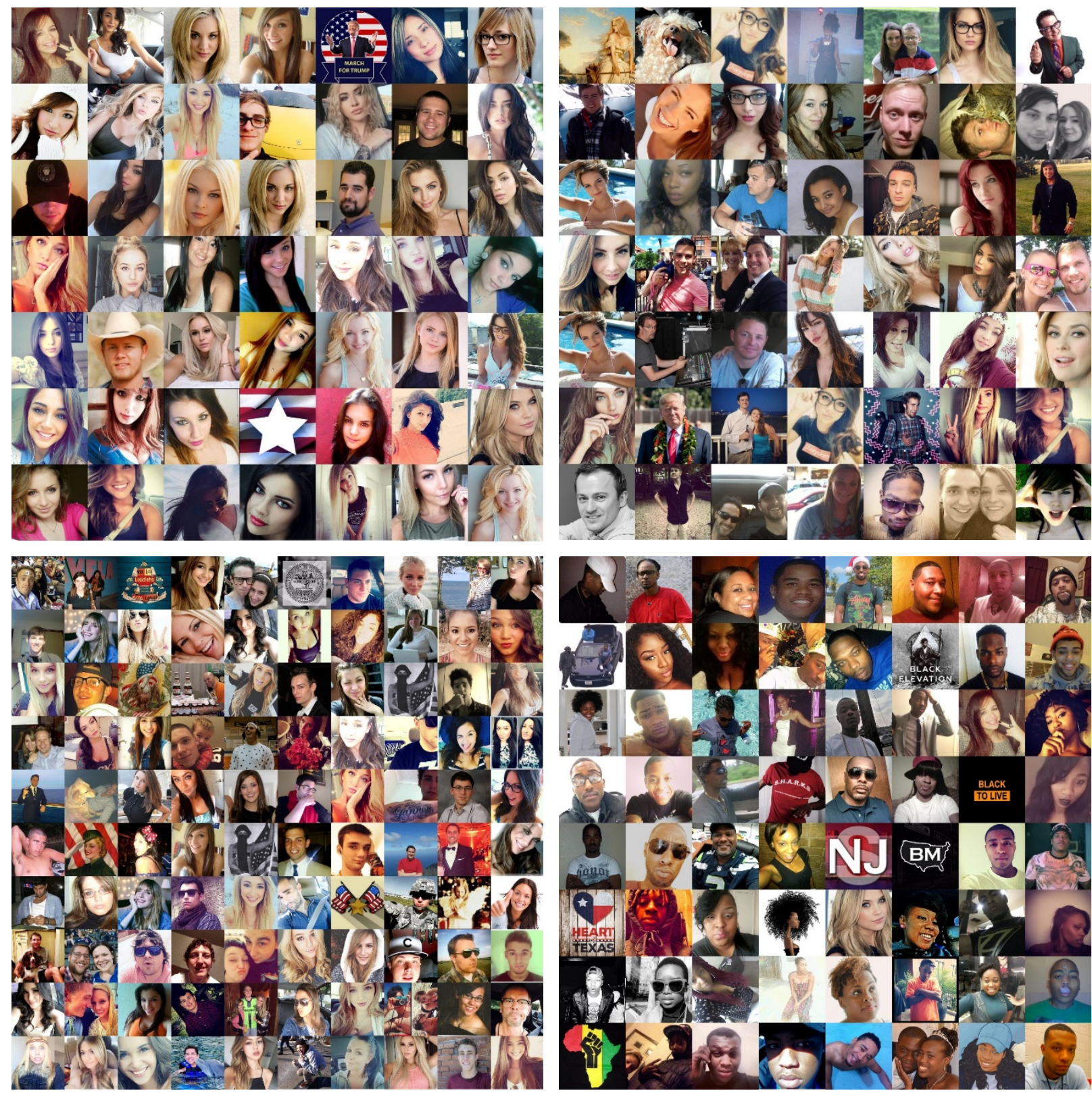


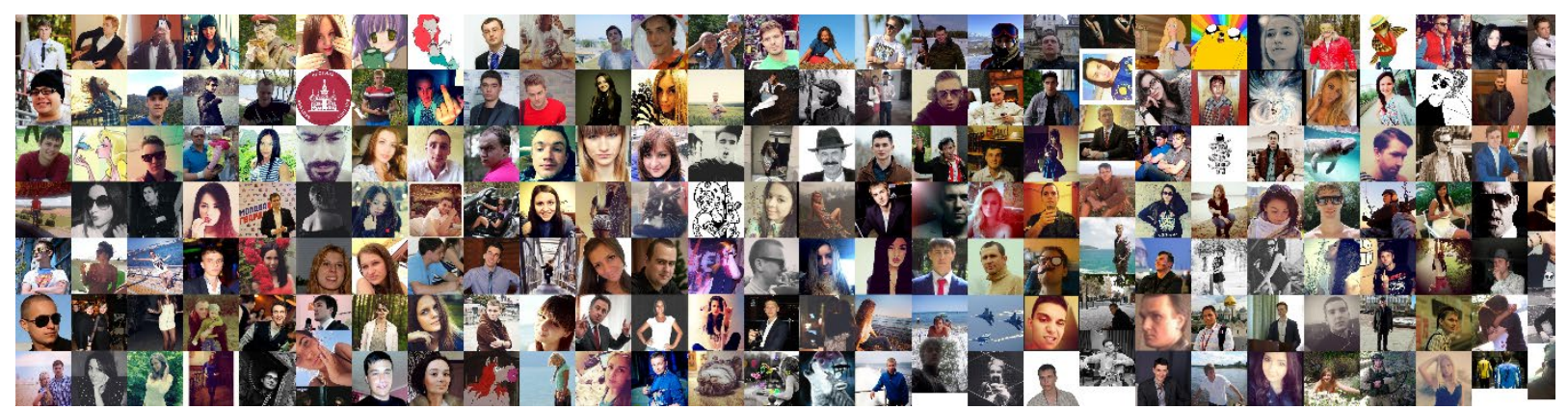

Figure 1: From left to right, Twitter profile pictures of Trump supporters, Christians, Conservatives, BlackLivesMatter activists, and self-identified Muscovites.

The multimodal information curated by IRA accounts was unpacked by imagecaptioning the Twitter profile images (Martinec \& Salway, 2005), so that their visual content was translated to text for downstream analysis. A visual inspection of the profile images, vis-à-vis the demographic group they targeted (Figure 1), shows that the semantic relationship in IRA multimodal content is of complementarity and not quite defined by the multimodal classes of illustration or anchorage $(s t a t=0)$. We collated the profile images of each of the five groups to apply pixel-level analysis that uncovers patterns in visual media and produces a largescale representation. We organized the profile images according to brightness and the color saturation of each image through an ImageMeasure2 plug-in for ImageJ (Rasband, 2012). Two members of the team, with expertise in professional photography, subsequently coded each of the images to identify features in the composition, framing, and photographic techniques employed to produce the profile image. The categories devised during the coding procedure are detailed in Table 1.

\begin{tabular}{|c|c|c|c|}
\hline File & 2625497896_profile.png & 2625539381_profile.png & 2671070290_profile.png \\
\hline Description & $\begin{array}{l}\text { White man swimming. } \\
\text { He plays with a dolphin } \\
\text { and smiles. }\end{array}$ & $\begin{array}{l}\text { Young white couple hugging } \\
\text { outdoors. Man wears glasses. } \\
\text { Woman smiles. Four other men } \\
\text { in the background. }\end{array}$ & $\begin{array}{l}\text { Young white man } \\
\text { smiling, wearing glasses, } \\
\text { and a black cap }\end{array}$ \\
\hline Race & W & $\mathrm{W}$ & W \\
\hline Composition & Close-up & Close-up & Close-up \\
\hline Angle & High angle & Neutral & Neutral \\
\hline Quality & Professional & Amateur & Amateur \\
\hline In/outdoor (I/O) & $\mathrm{O}$ & $\mathrm{O}$ & I \\
\hline People & 1 & 2 & 1 \\
\hline $\begin{array}{l}\text { Gender } \\
\text { (Male/Female/Group) }\end{array}$ & $\mathrm{M}$ & $\mathrm{G}$ & $\mathrm{M}$ \\
\hline Sensual (True/False) & $\mathrm{F}$ & $\mathrm{F}$ & $\mathrm{F}$ \\
\hline Emotion & Happy & Happy & Happy \\
\hline
\end{tabular}

Table 1: Coding categories applied to the Twitter profile image of Internet Research Agency accounts impersonating BlackLivesMatter, Christians, Conservatives, Muscovites, and Trump supporters

In addition to explicit categories, our inductive coding rendered a key category devised to identify whether the profile photo explored sensual undertones, a subtle feature and proxy for attractiveness present in many profiles featuring women or sexualizing the 
female body. Another key category devised during the coding process refers to the extent to which professional photographic techniques were employed to produce the image. Professional photographic work generates aesthetic elements that differ substantively from amateur photography, notwithstanding recent advances in smartphone cameras, particularly the expert use of hue, brightness, and light controls. We refer to this category as Quality to distinguish between professional-looking photos from those that are discernibly produced by users themselves. Finally, we triangulated the qualitative analysis with computer-assistant image processing using the bwimage $R$ package (Biagolini-Jr \& Macedo, 2019) to identify patterns in the groups of profile images.

\section{Results}

The IRA propaganda campaign resorted to ordinary individuals but unordinary attractive young women, often featured with professional makeup in professional-shot photos against a soft, balanced lighting. The chromatic and compositional variance identified in the profile photos show that US conservative groups are targeted with a composite of average young men and sensually crafted images of young women typical of soft advertisements employed by the cosmetic industry. The profile images in the Russians cohort, on the other hand, are marked by tropes of virility and domination. Emphasis is shifted from ordinary-looking male individuals to compositional undertones emphasizing power and adventure. BlackLivesMatter activists are framed with another compositional frame altogether; depicted largely with high angles projecting tense expressions in a single headshot. These compositional choices do not merely depict gender inequalities and gendered stereotypes but celebrate them.

The results are also consistent with the perceived notion that state-sponsored propaganda on social media exploits existing social tensions by framing contentious issues in a familiar but partisan light. IRA activity expertly pitched to Right-wing framings and beliefs, but the agency also targeted distinct sections of the US electorate, including liberal subgroups, chief of which were BlackLivesMatter activists. Religious, racial, and cultural groups are targeted with disguised social media accounts exploring biases and prejudices, but also perceived markers of membership of these groups. The multitude of targeted social groups, and the broad ideological spectrum of their interests, suggest that the target of the propaganda efforts is not the social groups the campaign chooses to personify, but social cohesion itself. The emphasis and perhaps exaggeration placed on existing social divisions is leveraged to amplify threats and ultimately erode social trust and social cohesion.

In the end, the guy next door represents a considerable departure from archetypes of heroic masculinity; indeed, the guy next door is the embodiment of unassuming, dependable, yet average masculinity. He is not just ordinary, but also local, thus submitting a sense of familiarity that effortlessly evolves to notions of reliability and trustworthiness. The visual trope of the affable guy next door may conceivably ease the labor-intensive costs of infiltration. Similarly, the cohort of implausibly attractive young women may follow a similar tactic of infiltration and subversion that exploits the male gaze and the depiction of women as sexual objects for the pleasure of the male viewer. However implausibly attractive they may be, this visual trope is seemingly an optimal candidate for becoming embedded with Trump supporters. 


\section{References}

Biagolini-Jr, C., \& Macedo, R. H. (2019). bwimage: A package to describe image patterns in natural structures. F1000Research, 8(1168), 1168.

Davis, S. E. (2018). Objectification, Sexualization, and Misrepresentation: Social Media and the College Experience. Social Media + Society, 4(3), 2056305118786727. doi: $10.1177 / 2056305118786727$

Elections Integrity. (2018). Data archive. from Twitter, Inc. https://about.twitter.com/en us/values/elections-integrity.html

Martinec, R., \& Salway, A. (2005). A system for image-text relations in new (and old) media. Visual communication, 4(3), 337-371.

Rasband, W. (2012). ImageJ: Image processing and analysis in Java. Astrophysics Source Code Library.

Romanets, M. (2017). Virtual warfare: Masculinity, sexuality, and propaganda in the Russo-Ukrainian war. East/West: Journal of Ukrainian Studies, 4(1), 159-177.

Seo, H. (2019). Visual Propaganda and Social Media. The SAGE Handbook of Propaganda, 126. 